\title{
Marx e a crítica à história como consciência: uma confrontação com a filosofia do sujeito
}

\author{
Sérgio Bacchi Machado ${ }^{1}$ \\ Instituto de Psicologia da Universidade de São Paulo
}

\begin{abstract}
Parte-se da hipótese de que a obra de Marx foi precursora da crítica à filosofia do sujeito, ou seja, à noção de história como consciência de si. Aborda-se, então, o método materialista dialético e sua análise do modo de produção capitalista, delineando-se alguns aspectos centrais das concepções marxistas de história e sujeito. Alcança-se, por fim, o conceito de práxis como correlato direto do entendimento do homem como ser social.
\end{abstract}

Palavras-chave: História, Sujeito, Karl Marx, Práxis.

Marx and the criticism towards history as self-consciousness: a confrontation with the philosophy of subject

The present article begins by the hypothesis that Marx's work was precursor of the criticism towards the philosophy of subject, that is, towards the notion of History as self-consciousness. The paper then approaches the dialectical materialist method and its analysis of the capitalist mode of production, delineating some central aspects of the Marxist conceptions regarding History and subject. Finally, it achieves the concept of praxis as a direct correlative of the understanding of man as a social being.

Keywords: History, Subject, Karl Marx, Praxis.

G $m$ sua Arqueologia do saber, obra original de 1969, Foucault (2004) debruça-se sobre os então novos paradigmas colocados pelo estudo histórico. Segundo ele, a nova disciplina histórica pode ser caracterizada por abandonar as antigas tradições metodológicas, resultando disso uma verdadeira mutação epistemológica em seu domínio. Silenciosamente, os historiadores deixaram de privilegiar concepções globalizantes, das quais todos os fenômenos derivariam. Noções totalizantes como "a evolução do pensamento humano" ou "o espírito de uma época", antes tidas como princípios organizadores das mais variadas relações materiais, foram relegadas ao segundo plano.

O objetivo de Foucault nessa obra era, por meio da descrição arqueológica de domínios discursivos, iluminar os novos problemas colocados pela disciplina histórica; no entanto, interessa-nos aqui o movimento por ele aludido de abandono dos operadores universalizantes. Dessa forma, torna-se necessário deslizarmos nossa atenção para os pressupostos das tradições rejeitadas, para percebermos, de fato, o que foi ultrapassado. Qual seria o perigo evitado por aquelas graves tradições que viam a história como um progressivo caminhar por espaços idênticos a ela mesma? Em que consistia esse grande medo da aparição do outro obscuro na superfície que deveria refletir justamente a tranqüilidade límpida do nosso olhar? Ora, a arqueologia foucaultiana nada mais é do que uma oposição estratégica a esses desertos imóveis e homogêneos, de forma que ela mesma, em sua dispersão material, nos fornece uma resposta. O que se perde é o princípio nuclear da antiga disciplina histórica, aquilo que Foucault denomina "filosofia do sujeito"; ou seja, abandona-se uma filosofia que

1 Psicólogo e mestre em psicologia pelo Instituto de Psicologia da Universidade de São Paulo. 
concebe o tempo "em termos de totalização, onde as revoluções jamais passam de tomadas de consciência" (Foucault, 2004, p. 14). Com efeito, o que está em questão é uma teleologia em que o devir é reduzido ao reencontro da consciência consigo mesma e a história é equacionada à vontade de um sujeito abstrato universal. Nesse sentido, a historia é concebida como cristalização da função fundadora do sujeito. Nessa história una, como que uma profecia se enuncia e, ao mesmo tempo, se realiza: o último homem, em seu último dia, reencontra nele mesmo o sorriso sereno e consolador de um Descartes, de um Montaigne, no fundo sempre o mesmo sorriso que acompanhou silenciosamente o primeiro homem sobre a Terra.

A ruptura da nova história com a filosofia do sujeito não é um evento banal, e pede alguma meditação por parte daqueles dentre nós ligados às práticas da psicologia focadas nas relações concretas de sujeitos que se constituem historicamente (Guirado, 1995). Realmente, a psicologia - que talvez seja a instituição em que os efeitos múltiplos das indissociáveis categorias história e sujeito se patenteiam de forma mais explosiva - encontra no corte com a filosofia do sujeito terreno fértil para uma compreensão da subjetividade irredutível às capacidades individuais (Guirado, 1995) e ao autocentramento (Birman, 2003). Evidentemente, o presente estudo se limita a abordar apenas alguns aspectos desse tema tão vasto e profícuo; contudo, esperamos oferecer alguns elementos para outras pesquisas que aceitem embrenhar-se nesse território.

De acordo com Foucault, a ruptura com a filosofia do sujeito encontra em Marx juntamente com Nietzsche - um de seus precursores. Seguindo essa direção apontada pela arqueologia foucaultiana, incidiremos no pensamento marxista e em sua concepção de história. Porém, antes de iniciarmos nosso percurso, algumas considerações fazem-se necessárias. Antes de tudo, devemos ter em mente que Marx segue Hegel e, num mesmo movimento, rompe com o mestre alemão.

\begin{abstract}
Meu método dialético, por seu fundamento, difere do método hegeliano, sendo a ele inteiramente oposto. Para Hegel, o processo do pensamento - que ele transforma em sujeito autônomo sob o nome de idéia - é o criador do real, e o real é apenas sua manifestação externa. Para mim, ao contrário, o ideal não é mais do que o material transposto para a cabeça do ser humano e por ela interpretado. [...] Em Hegel, a dialética está de cabeça para baixo. É necessário pô-la de cabeça para cima, a fim de descobrir a substância racional dentro do invólucro místico (Marx, 2002, pp. 28-29).
\end{abstract}

O corte com a dialética hegeliana não é inócuo. A partir dele, Marx atacará toda filosofia que, numa postura abstrato-contemplativa, se isole do curso da história. Realmente, a dialética materialista só se realiza como movimento crítico sobre formas sociais e históricas determinadas; não há possibilidade de ela efetivar-se a não ser quando se lança em matéria histórica viva. Tendo isso em vista, para compreender devidamente a natureza da crítica marxista aludida por Foucault à filosofia do sujeito, deveremos acompanhar de perto o deslocamento da dialética sobre o tecido social. Nesse trajeto, esboçaremos alguns princípios gerais, mas sempre teremos por base o traçado do pensamento marxiano no substrato social que ele pressupõe. Enfim, será necessária uma série de mediações para podermos atingir algumas concepções marxianas de história e de sujeito.

Nesse percurso, a possibilidade de banalizarmos o pensamento de Marx é constante, uma vez que, intencionalmente, transitaremos a passos largos - e talvez um pouco imprecisos - por essa filosofia tão rica em sua materialidade móvel. Esperamos, contudo, que essas rápidas incursões se prestem a lançar um pouco de luz aos problemas delimitados neste item introdutório. 
Em O capital, Marx (2002) analisa o modo de produção capitalista e suas relações de produção e de circulação; ou, em outras palavras, "a lei econômica do movimento da sociedade moderna" (2002, p. 18). Porém, o capitalismo, segundo Marx, não deve ser compreendido apenas no interior de seu modo de funcionamento - sendo esse o procedimento padrão dos economistas clássicos de quem Marx desejava se diferenciar. Seria necessário, portanto, buscar as condições de existência do capital fora dele, ou seja, antes dele. O método marxista conduz o pensamento aos "aspectos onde é necessário introduzir a análise histórica; neles a economia burguesa, mera forma histórica do processo de produção, aponta para mais além de si mesma, para os anteriores modos de produção" (Marx, 1977, p. 416). No entanto, para se efetuar a gênese histórica do capital, é preciso conhecer antes as relações fundamentais do capitalismo. Dessa forma, vemo-nos enredados num ciclo vicioso que postula a necessidade da análise histórica para a compreensão da atualidade e, simultaneamente, exige o conhecimento do mundo atual para se proceder a sua gênese. A solução marxista para esse impasse é o próprio método materialista dialético: a passagem do abstrato para o concreto. Segundo Marx, "para o pensamento, o método que consiste em elevar-se do abstrato ao concreto, é a maneira de apropriar-se do concreto, de reproduzi-lo como concreto pensado" (Marx, 1977, p. 25). Ao elevar-se do abstrato para o concreto, Marx executa deduções lógicas paralelas a análises históricas. Assim, o trabalho conceitual é a todo instante submetido à prova do desenvolvimento histórico, sendo o próprio movimento de confrontação o método dialético que constitui o conceito.

Tomemos como exemplo o conjunto concreto preços de mercadorias. Para compreendê-lo, Marx não o aborda diretamente como faziam normalmente os economistas empiristas, mas, antes, direciona seu olhar às categorias abstratas trabalho e valor ${ }^{2}$. Esse deslocamento não é artificial: as abstrações não perdem sua validade mesmo que sua forma abstrata deduzida se encontre diluída nas várias inervações do modo de produção capitalista. Torna-se possível, portanto, considerar a categoria valor, tanto logicamente como historicamente, antecedente aos preços de produção; partindo dela, o pensamento marxista eleva-se, num segundo momento, às formas mais concretas, uma vez que apenas na sociedade capitalista, cuja produção visa sempre o valor excedente, essa categoria se desenvolve plenamente. Com efeito, as categorias abstratas são apropriadas historicamente pelo capital industrial e somente nele atingem sua forma desenvolvida final. Assim, Marx demonstra como múltiplos atravessamentos do organismo socioeconômico pelo capital culminam na alteração da própria lei do valor. Isso ocorre pois, por meio dela, todos os agentes econômicos passam a relacionar-se uns com os outros como trocadores de mercadorias; e isso vale inclusive para a relação estabelecida entre capitalista e trabalhador - veremos adiante. Destarte, a dialética movimenta-se no espaço entre o lógico e o histórico, de modo que "a investigação lógica mostra onde começa o histórico, e o histórico completa e pressupõe o lógico" (Kosic, 2002, p. 60).

Por outro lado, a elevação ao concreto só pode ser desenvolvida no método por meio de uma série de mediações e vínculos. Daí o porquê de a passagem do estudo da mercadoria nos primeiros capítulos de $O$ capital - como uma espécie de célula embrionária em que as futuras contradições do modo de produção capitalista estariam condensadas - em direção às categorias concretas não se dar sem uma série de mediações. Explica-se aí também a impossibilidade de descrever as formas mais concretas da produção capitalista - tais como o sistema de crédito e a concorrência no mercado mundial - antes do funcionamento mais geral do capital. A importância das mediações para a dialética pode ser verificada na crítica marxiana ao método de Ricardo:

2 “O 'conceito' e a 'abstração', em uma concepção dialética, têm o significado de método que decompõe o todo para poder reproduzir espiritualmente a estrutura da coisa e, portanto, compreender a coisa” (Kosic, 2002, p. 18). 
Em vez de postular essa taxa geral de lucro, Ricardo deveria ter examinado até que ponto sua existência é de fato coerente com a determinação do valor pelo tempo de trabalho. Teria descoberto que, em vez de coerência, prima facia há contradição. A existência da taxa geral precisa ser explicada através de numerosos elos intermediários, em um procedimento muito diferente de sua simples subsunção à lei do valor (Marx, 1956, citado por Rosdolsky, 2001, p. 471).

\section{III}

Marx, logo no início de $O$ capital, incide seu olhar analítico na mercadoria. Como objeto palpável, sensível, a mercadoria atende a necessidades específicas: uma cadeira serva para sentar, com uma determinada quantidade de aço pode-se produzir o casco de uma embarcação, um livro espera ser lido. A qualidade desse uso potencial Marx denomina valor de uso. Portanto, o valor de uso corresponde à esfera qualitativa da mercadoria.

Marx nos faz observar, então, que, independentemente de seus valores de uso, as mercadorias são intercambiáveis entre si. A questão pode ser exposta da seguinte maneira: uma quantidade $\mathrm{x}$ de cadeiras pode ser trocada por uma quantidade y de aço, que, por sua vez, pode ser convertida em uma quantidade $z$ de livros. Já essa quantidade $z$ de livros pode tanto ser trocada por uma quantidade determinada de outra mercadoria qualquer quanto se converter na mercadoria inicial do elo, ou seja, x cadeiras. A capacidade dessas mercadorias de trocarem-se umas pelas outras induz a pensar que há nelas uma propriedade comum, um fator quantitativo geral e impalpável. Essa propriedade genérica das mercadorias recebe o nome de valor de troca ou, simplesmente, valor.

O valor de uma mercadoria refere-se às suas relações de troca, sendo independente de suas características físicas, geométricas ou de qualquer outra natureza. Nesse sentido, o valor de troca encontra-se na exterioridade do valor de uso ${ }^{3}$. "Põe-se de lado os valores-deuso das mercadorias, quando se trata da relação de troca entre elas." (Marx, 2002, p. 59.) Por conseguinte, os valores de troca referem-se a padrões meramente quantitativos, enquanto os valores de uso, posto que inseridos na esfera qualitativa, são irredutíveis uns aos outros.

Se atentarmos à grandeza do valor de troca de uma mercadoria, concluiremos que ela não é constante, mas se determina no espaço e no tempo. É preciso, aqui, retornarmos ao exemplo anterior: a quantidade de cadeiras passível de ser trocada, digamos, por três livros, varia de acordo com a época e a região em que a troca é efetuada. Essa informação tão simples dá uma pista preciosa a Marx - e, antes dele, a Ricardo - sobre a natureza do valor.

A solução para a questão do valor enquanto magnitude quantitativa abstrata é encontrada por intermédio de uma nova abstração relacionada à forma-mercadoria. Ora, sendo todas as mercadorias produtos de trabalho, não seria possível abstrair as qualidades específicas desses trabalhos, reduzindo todos a uma espécie geral e homogênea? Realmente, no trabalho humano abstrato as mercadorias encontram seu denominador comum; todas elas passam a ser vistas, então, como corporificações dessa espécie geral de trabalho. Em outras palavras, os produtos tornam-se valores-mercadorias.

Entretanto, se o valor de uma mercadoria corresponde à quantidade de trabalho abstrato nela armazenado, como poderíamos medir essa quantidade? A única resposta

\footnotetext{
3 Um olhar mais rigoroso mostra, entretanto, que essa exterioridade não é total, pois uma mercadoria qualquer, para ser potencialmente "trocável", deve atender a alguma necessidade social e, portanto, ter valor de uso para alguém. Entretanto, o valor de uso vigora, dessa maneira, como um mero índice da possibilidade de troca entre as mercadorias.
} 
possível é: pelo tempo de trabalho utilizado na produção daquela mercadoria. Nesse ponto, muitos já estão de pé para uma objeção óbvia: se o valor de uma mercadoria vincula-se ao tempo de trabalho abstrato gasto em sua produção, então um produtor mais "lerdo", que gaste, por exemplo, o dobro do tempo de seus pares para a confecção de uma mercadoria, deveria vendê-la por um valor muito superior ao cobrado por seus concorrentes. Empiricamente isso não se verifica; logo, invalidaria-se a teoria do valor proposta pela dialética materialista. Porém, a réplica de Marx é tão enfática quanto precisa:

Toda a força de trabalho da sociedade - que se revela nos valores do mundo das mercadorias - vale, aqui, por força de trabalho única, embora se constitua de inúmeras forças de trabalho individuais. Cada uma dessas forças individuais de trabalho se equipara às demais, na medida em que possua o caráter de uma força média de trabalho social e atue como essa força média, precisando, portanto, apenas do tempo de trabalho em média necessário ou socialmente necessário para a produção de uma mercadoria. Tempo de trabalho socialmente necessário é o tempo de trabalho requerido para produzir-se um valor-de-uso qualquer, nas condições de produção socialmente normais existentes e com o grau social médio de destreza e intensidade do trabalho (Marx, 2002, p. 61).

Voltemos ao exemplo do produtor de cadeiras. Durante uma década, ele produziu cerca de quatro cadeiras por dia, o que se aproxima da média produzida por seus pares no mesmo período. Todavia, surge uma nova ferramenta cujo emprego aumenta a produtividade de quatro para sete cadeiras por dia. Em tese, nosso artesão pode, contra a corrente geral, optar por continuar trabalhando conforme o antigo método, isto é, sem usar a nova ferramenta; o que ele não pode evitar é que cada unidade do seu produto se barateie, posto que o tempo de trabalho socialmente necessário para a produção diminuiu. Em outras palavras, apesar de sua rotina e seu método de trabalho não terem mudado, o tempo de trabalho socialmente necessário no setor alterou-se. Será significativa a conseqüência dessa alteração no desenvolvimento das forças de produção para produtor conservador: este passará a trocar a mesma quantidade de cadeiras de antes por uma quantidade muito menor de mercadorias, podendo chegar a ter sua subsistência ameaçada. Claro que, na realidade, ele não se deparará com esse problema, uma vez que também ele aderirá à ferramenta revolucionária; mas nos adiantemos um pouco em relação a nossa própria explanação e vejamos a situação desse homem daqui a mais alguns anos. Chegará o momento, com o avanço dos meios de produção, em que inventar-se-á uma nova ferramenta - ou mesmo uma máquina - cujo preço ultrapassará suas possibilidades de compra, de forma que ele não terá outra opção que não abandonar seu ofício ${ }^{4}$. Quando isso ocorrer, lhe restará apenas sua força de trabalho, e nós bem sabemos o que será feito dela. Vemos, portanto, como o valor, ao contrário de se situar na exterioridade da história, é uma abstração necessária à compreensão do próprio curso histórico, enraizando-se nele. equivale à

Estamos nos adiantando. Importa aqui é termos claro que a grandeza do valor

[...] quantidade de trabalho socialmente necessária ou o tempo de trabalho socialmente necessário para a produção de um valor-de-uso. Cada mercadoria individual é considerada aqui exemplar médio de sua espécie. Mercadorias que contêm iguais quantidades de trabalho, ou que podem ser produzidas no mesmo tempo de trabalho, possuem, conseqüentemente, valor da mesma magnitude. $\mathrm{O}$ valor de uma mercadoria está para o valor de qualquer outra, assim como o tempo de trabalho necessário à produção de uma está para o tempo de trabalho necessário à produção de outra (Marx, 2002, p. 61). 
Tomemos agora a seqüência de categorias delimitadas no livro I de $O$ capital, mercadoria-valor-dinheiro-capital (M-V-D-C). Essa sucessão lógica corresponde, simultaneamente, ao seu avanço histórico efetivo (Rosdolsky, 2001). Seguindo o fio condutor da obra derradeira de Marx, percebemos que cada categoria se prolonga e permite a seguinte. Porém, o mesmo se dá em sentido contrário: a categoria capital, por exemplo, só é compreendida integralmente quando consideramos também as categorias dinheiro, valor e mercadoria. Qual seria, então, o real grau de independência dessas formas que se ligam historicamente e estruturalmente? Ora, o dinheiro, por exemplo, realmente existiu antes do capital em épocas e sociedades em que não havia bancos ou trabalho assalariado; entretanto, apenas na sociedade onde predomina a produção capitalista pode o dinheiro assumir sua forma desenvolvida - o mesmo ocorrendo com o valor e com a mercadoria.

Desloquemos nosso foco para o trabalho, categoria usualmente tomada como simples e antiga - e sem dúvida, de certo modo, ela o é - que, todavia, sob o ponto de vista econômico, é bastante moderna, pois:

[...] a indiferença diante de um determinado tipo de trabalho pressupõe uma totalidade muito desenvolvida de tipos reais de trabalho, sem que nenhum deles predomine sobre os demais. [...] Por outro lado, essa abstração - o trabalho em geral - não é somente a expressão mental de uma totalidade concreta de trabalhos. A indiferença em relação a um trabalho particular corresponde a uma forma de sociedade na qual os indivíduos podem passar facilmente de um trabalho a outro e na qual o tipo específico de trabalho é, para eles, fortuito, e portanto indiferente (Marx, 1953, citado por Rosdolsky, 2001, p. $155)$.

Podemos, assim, vislumbrar com clareza como a dialética concebe as categorias econômicas de modo intrinsecamente relacionado às condições históricas. Nesse sentido, até mesmo aquela que talvez seja a mais abstrata das categorias - o trabalho - é delimitada pela conjuntura histórica.

Retornemos à cadeia M-V-D-C. Tendo em vista seu primeiro elo (mercadoriavalor), Marx escreve o célebre capítulo de $O$ capital sobre o fetichismo da mercadoria. Essa é uma passagem da obra marxista cuja ascendência no âmbito da psicologia não deve ser ignorada; nela está a análise dos efeitos objetivos e subjetivos da forma-mercadoria. Marx inicia o capítulo perguntando-se como é possível que as mercadoria pareçam aos homens dotadas de alma e vontade próprias, exercendo um fascínio não menor que o dos cultos religiosos. Pensemos na madeira, que, trabalhada pelo homem, assume a forma de mesa:

[...] a mesa ainda é madeira, coisa prosaica, material. Mas, logo que se revela mercadoria, transforma-se em algo ao mesmo tempo perceptível e impalpável. Além de estar com os pés no chão, firma sua posição perante as outras mercadorias e expande as idéias fixas de sua cabeça de madeira, fenômeno mais fantástico do que se dançasse por iniciativa própria (Marx, 2002, p. 93).

Podemos observar essa mesa pelos mais diversos ângulos, surpreendê-la em sua nudez de coisa e mesmo cerrá-la ao meio para inspecionar suas entranhas. Ainda assim, o enigma 
persiste, nossa pergunta "desmancha-se no ar" . É necessário que a dialética recorra à mediação de elementos históricos para que a mercadoria possa finalmente confidenciar o "segredo da sua alma". Marx faz, então, incidir seu pensamento no modo de produção feudal; lá, a dependência entre os agentes econômicos - servos e senhores feudais, vassalos e suseranos - é patente e marca tanto as relações sociais de produção quanto os outros âmbitos assentados nessa produção. Justamente em razão do caráter explícito de dependência dessas relações, os produtos não assumem uma feição fantasmagórica. O servo sabe qual é a parte dos seus produtos alienada e qual é a fração do seu tempo de trabalho voltado para o senhor. "O dízimo pago ao cura é mais palpável que sua bênção" (Marx, 2002, p. 99).

O modo de produção capitalista não lida com corvéia e dízimo, mas com mercadorias. É no interior do funcionamento da forma-mercadoria que Marx busca a solução de seu enigma. A mercadoria, afirma Marx, é fantasmagórica por ocultar a relação social constituída nos trabalhos individuais dos produtores e por deslocar essa relação para o próprio produto do trabalho específico. Os produtos do trabalho tornam-se, em sua forma fenomênica, por sua vez, os depositários das relações sociais de que eles originariamente resultam. Nesses jogos de sombras e contra-sombras, os produtores são substituídos pelas mercadorias em sua movimentação social.

Ataquemos essa elaboração marxiana por outro viés: no modo de produção capitalista, os objetos destinados ao uso assumem a forma de mercadorias. Uma das características fundamentais destas é o fato de que, como produtos do trabalho privado, elas são fabricadas de maneira independente. Por exemplo, os produtores de cadeiras dificilmente fazem também livros, de modo que uns produtores realizam seus trabalhos isolados dos outros. Evidentemente, na realidade, eles são muito mais dependentes entre si do que os agentes econômicos feudais, pois o capitalismo - ao contrário de outros modos de produção que mantêm uma relativa auto-suficiência de cada parte - é um organismo vivo totalmente interdependente. Porém, isso não se manifesta; ou melhor, se manifesta justamente no fetichismo da mercadoria. Voltemos aos produtores isolados de mesas e livros: o contato social se dá apenas no intercâmbio, no mercado; lá as formas sociais desses trabalhos privados podem se manifestar ${ }^{6}$. Contudo, isso não ocorre de forma "autêntica", posto que os produtores perderam o domínio de suas relações de produção e o controle sobre estas. Assim, estão dadas as condições para que se atribuam às mercadorias relações, vontade e mobilidade humanas, enquanto as verdadeiras relações sociais, ocultas pela mercadoria, se reificam. $\mathrm{O}$ fetichismo não é, portanto, um acidente incômodo, mas é o efeito inerente a um modo de produção constituído historicamente.

É necessário ainda destacar a forma-dinheiro como último elo dialético no fetichismo da mercadoria sem o qual este dificilmente teria a potência que tem. Marx combate veementemente os economistas que concebem o dinheiro exclusivamente como símbolo. Por meio da gênese lógico-histórica, ele demonstra que o dinheiro encontra sua origem na própria mercadoria - e não em uma representação simbólica dessa -, sendo a criação do dinheiro o equivalente à passagem de uma mercadoria específica para a forma-mercadoria universal. Esse transcurso corresponde, portanto, à criação do mediador universal. Assim, uma mercadoria singular torna-se:

5 Tomamos aqui no registro lúdico a linda frase contida em O manifesto comunista: "Tudo que é sólido desmancha-se no ar" (Marx \& Engels, 1998, p. 14.)

6 Podemos compreender melhor as últimas asserções se atentarmos no caráter da "indústria” patriarcal pré-capitalista, em que a produção voltada para a troca inexistia. Nela, "os fiandeiros e tecelões viviam sob um mesmo teto, a parte feminina da família fiava, enquanto a parte masculina tecia. Para as necessidades da própria família, o fio e o tecido eram produtos sociais; fiar e tecer eram trabalhos sociais dentro dos limites da família. Mas seu caráter social não consistia em trocar o fio (como equivalente geral) por tecido (como equivalente geral), ou trocar ambos, um pelo outro, como expressões indiferentes e igualmente válidas de um mesmo tempo geral de trabalho. O contexto familiar, com sua divisão natural do trabalho, dava ao produto do trabalho sua marca social peculiar" (Marx, 1956, citado por Rosdolsky, 2001, p. 113.) 
[...] mercadoria privilegiada, na qual pode expressar-se o valor de todas as demais de uma vez por todas, uma mercadoria que se torna encarnação direta do trabalho social e que, por isso, se torna direta e incondicionalmente intercambiável por todas as mercadorias: o dinheiro (Engels, 1956, citado por Rosdolsky, 2001, p. 115).

Entretanto, ao transfigurar-se em equivalente universal dos valores de troca, tornando-se a única mercadoria que, em sua função mediadora, se identifica com todas as demais, cria-se em torno ao dinheiro um espaço de isolamento e independência perante as outras mercadorias. Dessa maneira, o que era apenas a expressão quantitativa facilitadora das trocas personifica-se; em outras palavras, a função mediadora da mercadoria universal se perde, ao passo que o próprio dinheiro adquire autonomia ante os homens coisificados. Nesse ponto, as outras mercadorias já não mais são valiosas em razão da cristalização de trabalho social nelas embutido, mas sim por "conterem" uma determinada quantia de dinheiro. $\mathrm{O}$ fetichismo do dinheiro é, portanto, a contraparte do fetichismo da mercadoria; ou melhor, ele é o fetichismo da mercadoria elevado à máxima potência. $\mathrm{O}$ dinheiro, no capitalismo, esquece sua origem e observa os homens e seus trabalhos terrenos com olhar altivo?

Devemos ainda considerar a análise marxista da criação do dinheiro e da circulação como indispensável à configuração da teoria do valor. Isso porque é justamente na esfera da circulação - isto é, no intercâmbio dos produtos do trabalho entre os produtores - que um valor de uso se relaciona com outro como valor de troca. Efetivamente, no âmbito mercantil, os valor de uso fornecem, por meio de sua transitividade material, ou seja, da sua forma concreta móvel, as condições de possibilidade do valor de troca. Dessa forma, o modo de produção capitalista se diferencia dos demais por sustentar a seguinte contradição: "As variadas, determinadas, concretas e úteis espécies de trabalho, contidas nos corpos das diferentes mercadorias, consideram-se, agora, formas particulares de efetivação ou de manifestação do trabalho humano em geral" (Marx, 2002, p. 86). Somente dessa maneira os trabalhos específicos podem ser equacionados à forma-valor de seus produtos. Apenas na sociedade especializada na produção de mercadorias o trabalho particular pode se apresentar como a antítese dele mesmo, isto é, como trabalho indiferenciado e, nesse movimento de indistinção e anulação, mostrar sua face social.

Com o fetichismo, Marx demonstrou como o valor é fundamentalmente uma relação entre pessoas oculta sob um invólucro material (Marx, 2002). Entretanto, qual seria a natureza dessas relações? A resposta não seria encontrada na dimensão superficial da circulação mercantil, mas sim nas profundezas de outro mundo: a produção. Mas como descrever as relações de produção sem antes delinear o desenho do capital na superfície da circulação?

\section{V}

O processo de circulação mercantil simples é caracterizado por Marx como ciclo mercadoria-dinheiro-mercadoria, ou $\mathrm{M} \rightarrow \mathrm{D} \rightarrow \mathrm{M}$. O produtor tem, num primeiro momento, seu produto lançado no mercado; a mercadoria, sendo vendida, assume a forma-universal

\footnotetext{
7 Não devemos, contudo, pensar que Marx, como Proudhon, depositava no dinheiro a responsabilidade pelos males do capital. "Vemos como a 'degradação do dinheiro e a apoteose da mercadoria' defendida por Proudhon e outros, se baseia em um 'malentendido elementar sobre a conexão necessária entre mercadoria e dinheiro'. Não compreendem que toda a circulação de mercadorias deve levar à formação de dinheiro, e que por isso, 'enquanto o valor for a forma social dos produtos, é impossível eliminar o dinheiro"” (Rosdolsky, 2001, p. 101.) Conforme Marx, "enquanto as medidas se dirijam contra o dinheiro como tal, trata-se de apenas um ataque a conseqüências, cujas causas permanecem” (Marx, 1956, citado por Rosdolsky, 2001, p. 103).
} 
dinheiro. Ao adquirir valor de uso com o dinheiro da venda de seu produto, o produtor, agora consumidor, encerra o ciclo. Podemos resumir esse transcurso na fórmula sintética "vender para comprar". Dois pontos desse processo merecem destaque: a) não há criação de valor, o primeiro elemento do ciclo tem a mesma magnitude de valor que o último, cabendo ao dinheiro uma função de meio de circulação; b) ao tornar-se consumidor, o produtor original efetivamente encerra o ciclo. Evidentemente, novo ciclo poderá ser iniciado pelo produtor, porém tratar-se-ão de outros elementos e, portanto, de outro ciclo.

Marx detém-se, então, no ciclo do capital. Em seu movimento de valorização, o capital é caracterizado pelo seguinte ciclo: dinheiro-mercadoria-dinheiro, ou $\mathrm{D} \rightarrow \mathrm{M} \rightarrow \mathrm{D}+$; onde $\mathrm{D}+$ corresponde a $\mathrm{D}$ mais o excedente de valor produzido, ou mais-valor. Uma vez alcançado $\mathrm{D}+$, este será inserido novamente no processo de criação de valor. Destacaremos duas características do ciclo do capital as quais o diferenciam da circulação simples: a) nesse ciclo ocorre valorização, produzindo-se mais-valor; b) o ciclo não tem fim, uma vez que $\mathrm{D}+$ dará origem ao novo ciclo $\mathrm{D}+\rightarrow \mathrm{M} \rightarrow \mathrm{D}++$.

Considerando que o ciclo do capital pode ser sintetizado na fórmula "comprar para vender", ou seja, num movimento da circulação, nos deparamos com o problema aparentemente insolúvel da origem do mais-valor. Nas palavras de Marx:

A transformação do dinheiro em capital tem de ser explicada à base das leis imanentes da troca de mercadorias, e, desse modo, a troca de equivalentes serve de ponto de partida. Nosso possuidor de dinheiro, que, no momento, prefigura o capitalista, tem de comprar a mercadoria pelo seu valor, vendê-la pelo seu valor e, apesar disso, colher, no fim do processo, mais valor do que nele lançou. Sua metamorfose em capitalista deve ocorrer dentro da esfera da circulação e, ao mesmo tempo, fora dela. Tais são as condições do problema (Marx, 2002, pp. 196-197).

Para que o dinheiro possa se transformar em capital, é preciso que o possuidor de dinheiro ache, dentro do âmbito da circulação, no mercado, uma mercadoria um tanto especial. E se o capital é um valor em busca de mais-valor, a única coisa capaz de apresentarse diante dele como valor de uso seria algo com capacidade de reproduzi-lo e multiplicá-lo. $\mathrm{O}$ uso que o capital fará dessa mercadoria só pode corresponder ao o sentido de sua existência: criar mais-valor, ou seja, corporificar trabalho. Pois bem, essa mercadoria existe e chama-se força de trabalho ${ }^{8}$. Ao usá-la, o possuidor do dinheiro torna-se capitalista, ao passo que o dinheiro se transforma em capital.

A transação ocorre dentro da esfera da circulação. Não possuindo meios de produção como o capitalista, o indivíduo vende a mercadoria que detém: a força de trabalho contida em seu corpo vivo. Contudo, ele não aliena sua mercadoria para sempre - uma vez que isso implicaria a venda de si mesmo, ou seja, tornar-se escravo -, mas temporariamente. Assim, na condição de homem livre, ele vende sua força de trabalho por um tempo determinado, mantendo-se, em longo prazo, como seu proprietário.

Como ocorre com toda mercadoria, o valor da força de trabalho equivale ao tempo de trabalho nela corporificado. Dessa maneira, a conservação e a reprodução da força de trabalho correspondem à manutenção do corpo vivo do seu proprietário, ou seja, do trabalhador. Para sustentar-se, todo indivíduo necessita de uma quantidade mínima de meios de subsistência. Assim:

O tempo de trabalho necessário à produção da força de trabalho reduz-se, portanto, ao tempo de trabalho necessário à produção desses meios de subsistência, ou o valor da força de trabalho é o valor dos meios de subsistência necessários à manutenção de seu

8 Por força de trabalho entendemos "o conjunto das faculdades físicas e mentais existentes no corpo e na personalidade viva de um ser humano, as quais ele põe em ação toda vez que produz valores-de-uso de qualquer espécie” (Marx, 2002, p. 197). 
possuidor (Marx, 2002, p. 201).

Portanto, o mínimo valor da força de trabalho é dado pelo valor dos meios de subsistência imprescindíveis ao ser humano. Abaixo dessa linha, a capacidade de trabalho não pode mais se conservar.

O intercâmbio entre capital e trabalho é determinado por dois processos distintos. Ao comprar a força de trabalho, o capital adquire o próprio trabalho, ou seja, ele adquire a capacidade de conservar-se e multiplicar-se. Essa faculdade não pode surgir do valor da mercadoria comprada, mas do seu valor de uso. Para o trabalhador, por outro lado, a permuta se dá pela venda de sua força de trabalho em troca de uma quantia de dinheiro, o salário. "Para o trabalhador, esse intercâmbio é um ato de circulação mercantil simples, no qual sua mercadoria (a força de trabalho) percorre a forma de circulação M-D-M. Enquanto isso, o capital realiza o ciclo oposto, definido pela forma D-M-D." (Marx, 1956, citado por Rosdolsky, 2001, p. 173). Com efeito, para o trabalhador trata-se de um intercâmbio de equivalentes - força de trabalho por preço do trabalho -, ao passo que para o capital, uma vez que o capitalista recebe mais valor do que dá, ocorre um intercâmbio que contraria as próprias leis do intercâmbio.

A partir daí, podemos esmiuçar as relações de produção soterradas pela circulação. É hora de abandonarmos esse mundo inundado de luz, a circulação, para penetrarmos nos obscuros domínios da produção. Lá, o mistério da criação do valor excedente nos aguarda, envolto em ruídos ambíguos de máquinas e homens.

\section{VI}

O aproveitamento da força de trabalho nada mais é que o próprio trabalho, de forma que o capitalista consome a força de trabalho fazendo o trabalhador trabalhar. Do mesmo modo, "para o trabalho reaparecer em mercadorias, tem de ser empregado em valores-de-uso, em coisas que sirvam para satisfazer necessidades de qualquer natureza" (Marx, 2002, p. 211). Do ponto de vista do capitalista, o processo ocorre "entre coisas que o capitalista comprou, entre coisas que lhe pertencem" (Marx, 2002, p. 219). Assim, o capital alinha o trabalho vivo junto a seus elementos materiais, os meios de produção. No processo de produção, os elementos objetivos do capital submetem-se ao trabalho: "De um lado, a matéria que compõe o capital deve ser elaborada, ou seja, consumida pelo trabalho; de outro, a mera subjetividade [...] deve ser superada, objetivando-se na matéria do capital" (Marx, 1956, citado por Rosdolsky, 2001, p. 179). Entretanto, essa descrição, mesmo sendo precisa, não abarca o movimento específico do capital, assim como a indicação do valor.

Não temos como demonstrar neste espaço, mas consideramos que o capital constante - isto é, todo aquele não investido em força de trabalho - não altera a magnitude do seu valor no processo de produção9. Dessa forma, todo o valor empregado em matéria-prima, máquinas, etc., será transferido para a massa de produtos finais sem que, contudo, mais-valor seja produzido. A mágica deve ocorrer, portanto, no capital variável, ou seja, naquele relacionado à força de trabalho, ao trabalho vivo. Observemos, por conseguinte, o processo de produção e suas inerentes relações sociais sob o ponto de vista específico do valor. Imaginemos uma mercadoria cujo processo de produção envolva apenas capital constante, ou seja, zero trabalho humano. Nesse caso, pela lei da transferência, todo o valor será 
transmitido à massa de produtos finais ${ }^{10}$, impossibilitando, assim, a criação de mais-valor. Esse exercício imaginativo pode lançar luz a um aspecto central do modo de produção capitalista. Com efeito, caso o trabalhador recebesse como pagamento todo o valor que produziu com sua força de trabalho, não haveria valor excedente e, conseqüentemente, o modo de produção capitalista se inviabilizaria. Contudo, o trabalhador recebe, na realidade, apenas uma fração do valor que cria, consistindo o restante em mais-valia de propriedade do capitalista. Considerando uma jornada de trabalho de oito horas, o trabalhador usa, por exemplo, cinco horas para adicionar um valor à matéria equivalente ao seu salário diário. As três horas restantes, sendo tempo de mais-trabalho (sob o ponto de vista do trabalhador), serão convertidas em mais-valia (sob o ponto de vista do capitalista). Está concluído: o capital realizou sua mágica feia por meio da exploração do trabalho de outros.

Mas como explicar a característica mais evidente do modo de produção capitalista, aquela que o faz ultrapassar em eficiência e maleabilidade todos os outros modos de produção? Estamos falando da tendência do capital a revolucionar constantemente os meios de produção; tendência essa cujo efeito perceptível imediato é a criação de "forças produtivas mais maciças e colossais do que todas as gerações precedentes juntas" (Marx \& Engels, 1998, p. 17). Com efeito, sendo a produção de mais-valia por meio da extração de trabalho excedente o objetivo do capital, por que não perpetuar os meios objetivos da produção? Em outras palavras, por que sempre a produtividade como meta?

Consideremos, a título de exemplo, uma fábrica de tapetes. A jornada de trabalho de um operário nela empregado é de oito horas - manteremos os números do exemplo anterior -, sendo cinco horas desse total necessárias para corporificar um valor à matéria correspondente ao salário diário. Chamemos com Marx essas cinco horas de "tempo de trabalho necessário". As três horas restantes constituem o mais-trabalho e correlacionam-se diretamente com a produção de mais-valia. Denominemos "tempo de trabalho excedente" esse último período. Agora imaginemos que um novo método - uma nova máquina, por exemplo - acaba de ser inventado e nossa fábrica-exemplo passa a utilizá-lo em seu processo de produção. Como sabemos, de acordo com a lei da transferência de valores, a nova máquina transmitirá o custo de sua compra, de seu combustível e de sua manutenção ao valor total das mercadorias cujo processo produtivo ela passou a integrar. Por outro lado, essa máquina é capaz de substituir até cinco operários, aumentando significativamente a produção. Sua utilização é vantajosa para o capitalista, uma vez que a soma dos salários dos cinco trabalhadores - apesar de irrisória para o sustento desses homens - é muito mais elevada que os custos totais da máquina. Sejamos, contudo, tolamente otimistas: mesmo com a produtividade da fábrica crescendo sensivelmente, nenhum trabalhador é despedido. Entretanto, se o mais-valor é criado mediante a exploração do trabalho humano - conforme vimos anteriormente -, qual seria o ganho para o capitalista no uso da máquina em sua fábrica? Estaria a teoria do valor equivocada? Enfim, recaímos na questão inicial sobre o desenvolvimento dos meios de produção no capitalismo.

Tomemos, então, o seguinte cenário: a fábrica exemplificada é a primeira do setor a usar a máquina prodigiosa. Dessa forma, o trabalho morto - ou seja, aquele realizado pela máquina a um custo menor - terá o mesmo efeito no mercado que o trabalho humano. Isso é possível pois o "valor individual de cada uma dessas mercadorias [produzidas com o novo método] fica então abaixo de seu valor social, isto é, custa menos tempo de trabalho do que o imenso volume dos mesmos artigos produzidos nas condições sociais médias" (Marx, 2002, p. 368). Esse efeito singular só pode se concretizar pois outras fábricas utilizam ainda "obsoletas" mãos humanas para fazer o trabalho que em nossa fábrica a máquina executa. Conseqüentemente, o tempo de trabalho necessário na fábrica-exemplo diminui na mesma proporção em que o tempo de trabalho excedente aumenta. Ou seja, o capitalista "pioneiro"

10 Consideramos aqui a produção em condições sociais normais, ou seja, sem desperdício de matérias-primas, com intensidade média de trabalho etc. 
consegue produzir mais valor excedente que seus concorrentes. Enquanto durar esse descompasso na produtividade entre essa fábrica-exemplo e as demais, nosso capitalista dormirá feliz ${ }^{11}$.

Por esse exemplo da fábrica de tapetes explica-se a inclinação do capital pelo desenvolvimento das forças de produção.

Chamo de mais-valia absoluta a produzida pelo prolongamento do dia de trabalho, e de mais-valia relativa a decorrente da contração do tempo de trabalho necessário e da correspondente alteração na relação quantitativa entre ambas as partes componentes da jornada de trabalho (Marx, 2002, p. 366).

A mais-valia relativa é fenômeno peculiar ao capitalismo industrial, sendo o resultado de um processo histórico que levou a divisão social do trabalho ao seu limite. Veremos no próximo item, em linhas gerais, como isso ocorreu.

Antes, porém, gostaríamos de destacar um grave aspecto do conceito de mais-valia. Vimos que o elemento final do ciclo do capital $\mathrm{D} \rightarrow \mathrm{M} \rightarrow \mathrm{D}+$ é direcionado novamente ao processo de produção. Assim, $\mathrm{D}+$ (que consiste em $\mathrm{D}$ mais o mais-valor produzido) torna-se o primeiro elemento do novo ciclo $\mathrm{D}+\rightarrow \mathrm{M} \rightarrow \mathrm{D}++$. Porém, $\mathrm{D}+$ difere em um aspecto essencial da maneira pela qual tendemos a conceber D: ele é mais-valia capitalizada. Desaparece, assim, a premissa ilusória de que o capital cria valor essencialmente na esfera da circulação. Com efeito, elimina-se o mito que envolve a acumulação primitiva do capital, tomando seu lugar um acontecimento histórico do modo de produção capitalista. Logo, D+ encontra, na própria exploração do trabalho alheio, sua origem e sua finalidade - o aumento da escala dessa exploração. Evidencia-se, desse modo, que "o motivo que impele e o objetivo que determina o processo de produção capitalista é a maior expansão possível do próprio capital, isto é, a maior produção possível de mais-valia, portanto, a maior exploração possível da força de trabalho" (Marx, 2002, p. 384). Podemos, então, verificar como o trabalho se depara com as condições objetivas de produção que ele mesmo proporcionou. Essa constatação é contundente, pois ela indica que "o trabalhador não só produziu a riqueza alheia e a própria pobreza, mas também [produziu e continua produzindo] a relação entre essa riqueza [...] e ele mesmo como pobreza" (Marx, 1977, p. 408). Desse modo, "o processo capitalista de produção, considerado em sua interdependência ou como processo de reprodução, não só produz mercadorias, não só produz mais valia-valia, mas produz e reproduz a própria relação capitalista: de um lado o capitalista, de outro o assalariado" (Marx, 2002, p. 607).

\section{VII}

Marx realiza em $O$ capital uma sólida análise das condições históricas concretas que possibilitaram a configuração do modo de produção capitalista. Partindo da Baixa Idade Média, ele demonstra como a população excedente, originária do declínio do modo de produção feudal, dirigiu-se às futuras cidades, os burgos. Estes existiam de modo bastante isolado uns dos outros, prestando tributos aos senhores feudais que, em contrapartida, lhes asseguravam proteção militar.

11 Quanto mais avançado é o estágio do modo de produção capitalista, menor é o intervalo de tempo entre a criação de um novo método de produção e sua "cópia" pelas indústrias concorrentes. 
As organizações produtivas características dos burgos eram as corporações de ofício. Essas corporações garantiam o monopólio de seus ramos de atividade inibindo a concorrência entre os que produziam um mesmo artigo e controlando a qualidade dos produtos. Ao condenar a usura, as corporações assumiam uma postura eminentemente feudal. Porém, simultaneamente, elas conseguiam assegurar o crescimento da vida urbana por meio do incremento comercial. Com isso, muitos burgos passaram a reivindicar autonomia, de modo que um embate com as estruturas feudais foi inevitável para a emancipação das incipientes cidades.

No plano das relações de produção, as corporações eram regidas por uma hierarquia de forma piramidal. O topo era ocupado pelo mestre-artesão, o qual também era proprietário das ferramentas, da matéria-prima e dos produtos finais. A base era preenchida, por sua vez, pelos aprendizes, que, em troca de seu trabalho, recebiam do mestre moradia, alimentação e vestuário. Caso a corporação autorizasse, o aprendiz poderia tornar-se mestre e ter sua própria oficina. É de se destacar, ainda, que a força da corporação era tal que ela determinava inclusive o número de aprendizes em cada oficina, o qual era geralmente bastante reduzido. Obviamente, mestres e aprendizes exerciam seu ofício em toda a extensão, isto é, trabalhavam a matéria-prima em todos os estágios até o produto final.

As corporações de ofício eram, portanto, organizações predominantemente patriarcais, ou seja, marcadas por relações do tipo "mestre-aprendiz". Devido à natureza dessas relações, o aprendiz não era separado totalmente dos meios de produção. Realmente, "o trabalhador e seus meios de produção permaneciam indissoluvelmente unidos, como o caracol e sua concha, e, assim, faltava a base principal da manufatura: a separação do trabalhador de seus meios de produção e a conversão desses meios em capital" (Marx, 2002, p. 414). Mas o que é a base da manufatura se não o nascimento do modo de produção capitalista?

Surge, então, o problema da acumulação primitiva do capital. Segundo Marx, ela ocorre:

[...] simplesmente quando, através do processo histórico de dissolução do antigo modo de produção, o valor existente como riqueza monetária adquire, por um lado, a capacidade de comprar as condições objetivas do trabalho e, por outro, a de trocar por dinheiro o trabalho vivo dos trabalhadores livres. Todos esses elementos existiam; sua separação é um processo histórico, um processo de dissolução, e é esse processo que permite ao dinheiro transforma-se em capital (Marx, 1977, pp. 460-461.)

Dessa forma, Marx compreende as corporações de ofício como formações híbridas, configuradas por elementos do antigo modo de produção feudal que, contraditoriamente, apontam para o futuro capitalismo ${ }^{12}$. Não por acaso, na aurora do capitalismo, o ainda frágil capital se limita a utilizar os métodos de produção então vigentes nas corporações. Dessa maneira, ele inicia seu percurso contratando dispersos tecelões manuais em suas próprias moradias. Entretanto, logo essa coordenação apenas formal do capital sobre os trabalhadores se transforma em domínio efetivo sobre o trabalho. Seu primeiro movimento consiste na passagem da relação individual isolada de cada trabalhador para aquilo que Marx chama de cooperação simples. Esta é definida pela atividade coordenada de "um número de trabalhadores relativamente grande, no mesmo momento e no mesmo espaço [...], para produzir o mesmo tipo de mercadorias, sob o comando do mesmo capitalista" (Marx, 1956, citado por Rosdolsky, 2001, p. 203). Uma vez alcançada a cooperação simples, o capital anima-se a dar mais um passo. Com efeito, surge o momento em que a empresa capitalista primitiva se vê pressionada a dividir o trabalho total em operações parciais, destinando a cada 
trabalhador ou grupo de trabalhadores uma dessas operações. Esse é o princípio de uma tendência que a manufatura, sem dúvida, levará até as últimas conseqüências. Realmente, a divisão social do trabalho será conduzida pela manufatura até o nível da capilaridade. Para isso, ela formará um trabalhador não mais apto a agir em todas as etapas da produção de um artigo, mas sim um autômato programado para repetir uma tarefa específica. Essa tarefa pode ser microscópica, como o giro de um parafuso; ou vigorosa, como a pressão sobre um ferrolho; o que importa é que algo sempre se repete, e o que se repete é a própria repetição. Cínico e realista é o texto de um "teórico" dessa época selecionado por Marx:

A ignorância é a mãe da indústria e da superstição. O raciocínio e a imaginação estão sujeitos a erros; mas é independente de ambos um modo habitual de mover a mão ou o pé. Por isso, as manufaturas prosperam mais onde mais se dispensa o espírito e onde a manufatura pode ser considerada uma máquina cujas partes são seres humanos (Ferguson, 1767, citado por Marx, 2002, p. 417).

Porém, isso foi apenas um preâmbulo para o derradeiro ato do capital. O desenvolvimento dos meios de produção tornou pequeno o palco delimitado pela manufatura. Com efeito, no dia em que a primeira máquina foi acionada no processo de produção, o capital pôde desfazer o último vínculo do trabalhador com seu produto. Nesse dia, o trabalhador tornou-se um mero supervisor da máquina, um apêndice da máquina, uma quase-máquina. Também suas relações sociais tomaram como modelo as engrenagens mecânicas, pois tudo os levava a crer que eles haviam se transformado em "complementos vivos de um mecanismo morto que existe independente deles” (Marx, 2002, p. 482).

\section{VIII}

O que vemos como movimento social das coisas - esclarece a dialética - é, essencialmente, a ocultação das relações sociais dos homens. Porém, o fato de as relações sociais se apresentarem aos homens em sua forma subvertida, ou seja, como qualidades sociais das coisas, é condicionado por determinações históricas que o ultrapassam. Nesse sentido, a configuração histórica da forma social do trabalho que cria valor de troca é, como vimos, o pressuposto fundamental da reificação das relações sociais. $O$ pleno desenvolvimento das contradições já presentes como embrião na forma-mercadoria corresponde ao desenvolvimento do capital enquanto formação socioeconômica. Com efeito, o capital só pode se realizar por meio das relações coisificadas entre os homens.

A ideologia nos faz acreditar que o real fetichizado é a ordem natural e espontânea do mundo. A dialética, por sua vez, não nega o fato de que os homens foram submetidos ao domínio das coisas; ela nega é que a realidade reificada das relações sociais exista independentemente da ordem capitalista. Dessa forma, as relações petrificadas integram a ordem capitalista, a qual é somente um modo histórico de produção a ser superado. A análise marxista, longe de aceitar a reificação como condição humana natural, demonstra que o movimento das mercadorias é uma forma histórica de relação entre os homens. Ao aceitar as relações sociais fixadas pelas coisas, a ideologia identifica-se com as determinações econômicas vigentes. A revelação da ideologia como forma fenomênica necessária ao modo de produção capitalista empreendida pela dialética tem, como contraparte, a análise crítica da formação socioeconômica capitalista. Assim, o desvendamento das formas fenomênicas do capital complementa-se com a gênese crítica do próprio modo de produção capitalista. 
Portanto, longe de desconsiderar a realidade reificada da cultura totalizante ${ }^{13}$, o pensamento marxista alcança seu autêntico objeto histórico por meio do exame crítico das formas reificadas. Somente aí ele pode elevar-se do abstrato para o concreto e afirmar com propriedade que a ideologia não se relaciona com uma qualidade natural da realidade, mas ela é o reflexo de determinadas condições históricas petrificadas. Dessa maneira, a focalização das formas reificadas pelo método dialético acarreta, para aquelas, a destruição de sua pretensa naturalidade e a enunciação do seu caráter derivado e mediato. Por outro lado, ao submeter-se às práticas fetichizantes, a ideologia desconsidera um conceito muito caro à dialética materialista: a práxis.

Não é exagero afirmar que todo o presente trabalho, desde seu início, foi atravessado pelo conceito de práxis. Porém, só agora, após quase termos concluído o itinerário pelo pensamento marxista a que nos propusemos, podemos abordar esse conceito. De acordo com Marx, em sua argumentação contra o materialismo de Feuerbach:

A falha capital de todo materialismo até agora (incluso o de Feuerbach) é captar o objeto, a efetividade, a sensibilidade apenas sob a forma de objeto ou de intuição, e não como atividade humana sensível, praxis; só de um ponto de vista subjetivo. [...] Feuerbach quer objetos sensíveis - efetivamente diferenciados dos objetos de pensamento, mas não capta a própria atividade humana como atividade objetiva (Marx \& Engels, 1974, p. 57).

O real é o mundo da práxis humana. Nesse sentido, a realidade é um complexo de relações sociais que os homens instauram na produção e no vínculo com os meios de produção. Entretanto, isso não equivale a alinhar a dialética a um reducionismo econômico estreito. Ao contrário, por meio do conceito de práxis, a dialética desvincula-se de uma certa vertente vulgar estabelecida por alguns marxistas segundo os quais os fenômenos da cultura, da política ou da filosofia devem ser integralmente reduzidos ao simples fator econômico. A dialética é, isso sim, o método da "explicitação dos fenômenos culturais partindo da atividade prática objetiva do homem histórico" (Kosic, 2002, p. 39). Desse modo, a radicalidade da dialética consiste em penetrar até as raízes da realidade social, isto é, até a práxis enquanto atividade humana sensível.

Conceber a atividade humana como práxis possibilita o dimensionamento do sujeito concreto enquanto criador da realidade social que, ao mesmo tempo, é por ela criado. Assim, o homem se torna na práxis um ser social. Com efeito, a práxis corresponde à esfera de criação do homem como ser histórico social. Somente por esse viés podemos entender a análise das categorias econômicas realizada por Marx. O que se empreendeu com a análise daquelas categorias foi nada menos que a delimitação das formas fundamentais de objetivação do homem como ser social. Uma vez estando as categorias econômicas atravessadas pelo o conceito de práxis, cria-se a possibilidade de articular simultaneamente, isto é, num mesmo movimento, produção de riquezas e objetivação dos indivíduos. Nas palavras de Marx:

No ato mesmo da reprodução não se modificam apenas as condições objetivas - por exemplo, uma vila torna-se uma cidade, um deserto torna-se terra cultivável; modificam-se os próprios produtores, enquanto extraem novas qualidades de si mesmos, desenvolvem-se na produção e se transformam, criam novas forças e novas representações, novos modos de relações, novas exigências e uma nova linguagem (Marx, 1977, p. 447).

13 "É profundamente errônea a hipótese de que a realidade no seu aspecto fenomênico seja secundária e desprezível para o conhecimento filosófico e para o homem: deixar de parte a aparência fenomênica significa barrar o caminho do conhecimento do real" (Kosic, 2002, p. 68). 
Mas o que é a dialética materialista se não a produção de um conhecimento que é, ao mesmo tempo, práxis revolucionária?

Retomemos a nossa questão inicial para um breve arremate. A concepção de história como desenrolar da consciência é demolida em sua base pela dialética marxiana. O que Marx desafia com seu método é a especulação que faz:

[...] da história recente a finalidade da história anterior; é assim, por exemplo, que se atribui à descoberta da América o seguinte objetivo: ajudar a eclodir a Revolução Francesa; dessa maneira, confere-se então à história seus fins particulares e dela se faz "uma pessoa ao lado de outras pessoas" (Marx \& Engels, 2007, p. 47).

Contrapondo-se a essa visão teleológica-subjetivista, a dialética elege a práxis como núcleo de sua rede conceitual e demonstra que:

[...] a história não se acaba resolvendo em "consciência de si", como "espírito do espírito", mas sim que a cada estágio são dados um resultado material, uma soma de forças produtivas, uma relação com a natureza e entre os indivíduos, criados historicamente e transmitidos a cada geração por aquela que a precede, uma massa de forças produtivas, de capitais e de circunstâncias, que, por um lado, são bastante modificados pela nova geração, mas que, por outro lado, ditam a ela suas próprias condições de existência e lhe imprimem um determinado desenvolvimento, um caráter específico; por conseguinte as circunstâncias fazem os homens tanto quanto os homens fazem as circunstâncias (Marx \& Engels, 2007, p. 36).

Portanto, retira-se a história de seu solo absoluto, de sua substância imutável, enfim, de sua "anti-historicidade". Todavia, esse absoluto exterior à história é também exterior ao homem, uma vez que existe independentemente da práxis humana. De fato, "a sociedade enquanto sujeito" (Marx \& Engels, 2007, p. 35) encontra sua cara-metade na razão cartesiana do indivíduo apartado e emancipado, o qual tem na própria consciência o fundamento de si e do mundo. Contrapondo-se a isso, $\mathrm{O}$ capital inteiro pode ser lido sob o prisma de que o sujeito não é uma substância exterior à história, mas ele se cria justamente no movimento da história. Nesse sentido, "o conhecimento de quem é o sujeito significa conhecimento da atividade do próprio sujeito no mundo" (Kosic, 2002, p. 183).

Talvez mais significativa que a simples constatação da antinomia entre a obra de Marx e a filosofia do sujeito seja a forma singular com que a dialética marxiana procede nessa confrontação. Gostaríamos de pensar que o presente trabalho oferece alguns elementos para esclarecer essa questão.

\section{Referências}

Birman, J. (2003). Mal-estar na atualidade: a psicanálise e as novas formas de subjetivação. Rio de Janeiro: Civilização Brasileira.

Marx, K. (2002). O capital: crítica da economia política (vols. 1 e 2). Rio de Janeiro: Civilização Brasileira.

Marx, K. (1977). Lineas fundamentales de la crítica de la economía política (grundrisse) (vol. 1). Barcelona: Crítica.. 
Marx, K \& Engels, F. (1974). Teses contra Feuerbach (Coleção Os Pensadores, vol. 35). São Paulo: Abril Cultural.

Marx, K \& Engels, F. (1998). O manifesto comunista. Rio de Janeiro: Paz e Terra.

Marx, K \& Engels, F. (2007). A ideologia alemã. São Paulo: Martins Fontes.

Foucault, M. (2004). A arqueologia do saber. Rio de Janeiro: Forense Universitária. (Originalmente publicado em 1969. Título original: L'Archéologie du savoir).

Guirado, M. (1995). Psicanálise e análise do discurso: matrizes institucionais do sujeito psíquico. São Paulo: Summus.

Guirado, M. (1987). Psicologia institucional. São Paulo: EPU.

Kosik, K. (2002). Dialética do concreto. Rio de Janeiro: Paz e Terra.

Rosdolsky, R. (2001). Gênese e estrutura de O capital de Karl Marx. Rio de Janeiro: Contraponto.

\section{Endereço para correspondência}

bacchimachado@gmail.com 